\title{
Effects of Annealing Temperature on Thermoelectric Properties and Microstructure of $\mathrm{Ag}_{0.6} \mathrm{~Pb}_{18} \mathrm{Sb}_{5} \mathrm{Te}_{20}$
}

\author{
Tao-Hsing Chen, ${ }^{*}$ Shiang-An Tsai, and Ting-Yang Zeng \\ Department of Mechanical Engineering, National Kaohsiung University of Applied Sciences, \\ No. 415, Jiangong Rd., Sanmin Dist., Kaohsiung City 80778, Taiwan
}

(Received May 2, 2017; accepted October 5, 2017)

Keywords: vacuum arc furnace, thermoelectric materials, thermoelectric properties, figure of merit, ZT

$\mathrm{PbTe}$ and $\mathrm{Sb}_{2} \mathrm{Te}_{3}$, two of the most common thermoelectric materials, have stable mid- and high-temperature thermoelectric properties. Both can be tuned as either N-type or P-type semiconductors. The figure of merit (ZT) values of the $\mathrm{PbTe}$ and $\mathrm{Sb}_{2} \mathrm{Te}_{3}$ thermoelectric materials currently available on the market are around 0.8 and close to 1 , respectively. In this study, $\mathrm{Pb}_{18} \mathrm{Sb}_{5} \mathrm{Te}_{20}$ was used as a substrate and $\mathrm{Ag}$ was then added to form an $\mathrm{Ag}_{0.6} \mathrm{~Pb}_{18} \mathrm{Sb}_{5} \mathrm{Te}_{20}$ alloy. $\mathrm{A}$ comparison of thermoelectric properties between test pieces annealed at temperatures of 200, 400, and $600{ }^{\circ} \mathrm{C}$ and unannealed ones was conducted. The results revealed that the $\mathrm{Ag}_{0.6} \mathrm{~Pb}_{18} \mathrm{Sb}_{5} \mathrm{Te}_{20}$ alloy annealed at $600{ }^{\circ} \mathrm{C}$ had the best thermoelectric properties. The experimental methods used in this study included the preparation of bulk material using vacuum arc melting, X-ray diffration (XRD) analysis, a comparison with the Joint Committee on Powder Diffraction Standard (JCPDS) database to confirm the face-centered rhombohedral crystal structure, and a study of thermoelectric properties such as the Seebeck coefficient, thermal conductivity, and resistivity. The objective is the improvement of the material thermoelectric figure of merit ZT.

\section{Introduction}

Thermoelectric materials are capable of transforming heat into electricity, or electricity into heat. They can be used in generating electricity or in thermoelectric cooling because the heat can be transformed into electrical energy, which consequently lowers the temperature. Lead telluride is the most commonly used thermoelectric material in a mid-temperature environment and some thermoelectric materials have been made into thermoelectric sensors to detect the waste heat. ${ }^{(1-4)}$ It has been reported ${ }^{(5)}$ that $\mathrm{Ag}$ doped into lead telluride improved the electrical properties. Sb can also be added at $700 \mathrm{~K}$ to form a p-type semiconductor, which improves the figure of merit (ZT) value by 1.5 . PbTe is useful between $573-873 \mathrm{~K}$, and in addition to its thermoelectric properties, it can also be used in thermoelectric heating. ${ }^{(6-10)}$ There are two ways of increasing the ZT value: by lowering the thermal conductivity coefficient $(\kappa)$ or raising the power factor $\left(S^{2} \sigma\right)$. However, the power factor is determined by, for example, the density of states, scattering parameter, carrier mobility, and position of the Fermi level, which are categorized as intrinsic properties of the material and cannot be altered during the preparation process. Various degrees of doping were used in our experiments to change the Fermi level of the material and achieve a higher power factor. ${ }^{(11)}$

${ }^{*}$ Corresponding author: e-mail: thchen@cc.kuas.edu.tw http://dx.doi.org/10.18494/SAM.2017.1737 
The aim is to attain full crystallization and improve the overall thermoelectric property of the bulk material by annealing. Furthermore, we also want to increase the effect of thermoelectric sensors.

\section{Materials and Methods}

The experiments carried out in this study involved bulk material preparation, composition and structural analyses, microstructural analysis, and measurement of thermoelectric properties. Powdered Ag (99.9\%), Pb (99.99\%), Sb (99.99\%), and Te (99.99\%) were mixed according to the desired mole ratios and formed into pellets in a hydraulic press. The pellets were smelted to form a quaternary alloy system $\mathrm{Ag}_{0.6} \mathrm{~Pb}_{18} \mathrm{Sb}_{5} \mathrm{Te}_{20}$. The smelted alloys were melted under vacuum in an arc furnace (three times) to form cast ingots. These were cut into test pieces of the appropriate dimension with a low speed cutter and machine polished. The analyses performed on the test pieces included composition and structural analysis, microstructural analysis, and Seebeck coefficient measurement. The ZT value of the test pieces was calculated from properties such as the Seebeck coefficient, coefficient of resistivity, and coefficient of thermal conductivity. An assessment of the thermoelectric properties and comparisons with data from published research were carried out. In addition, X-ray powder diffraction and field emission scanning electron microscopy (FESEM) were also used to investigate the composition and microstructure of all the alloys used in these experiments.

\section{Results and Discussion}

\subsection{X-ray diffraction (XRD) microstructural analysis of $\mathrm{Ag}_{0.6} \mathrm{~Pb}_{18} \mathrm{Sb}_{x} \mathrm{Te}_{20}$ alloys annealed at different temperatures}

The XRD plots of $\mathrm{Ag}_{0.6} \mathrm{~Pb}_{18} \mathrm{Sb}_{5} \mathrm{Te}_{20}$ alloys annealed at temperatures of 200,400 , and $600{ }^{\circ} \mathrm{C}$ for $72 \mathrm{~h}$ are shown in Fig. 1. A comparison of the results with the Joint Committee on Powder Diffraction Standard (JCPDS) database indicates that the main crystal structure of these alloys was $\beta$-PbTe, which is in the space group Fm3m and comprises two interwoven face-centered cubic (FCC) lattices.

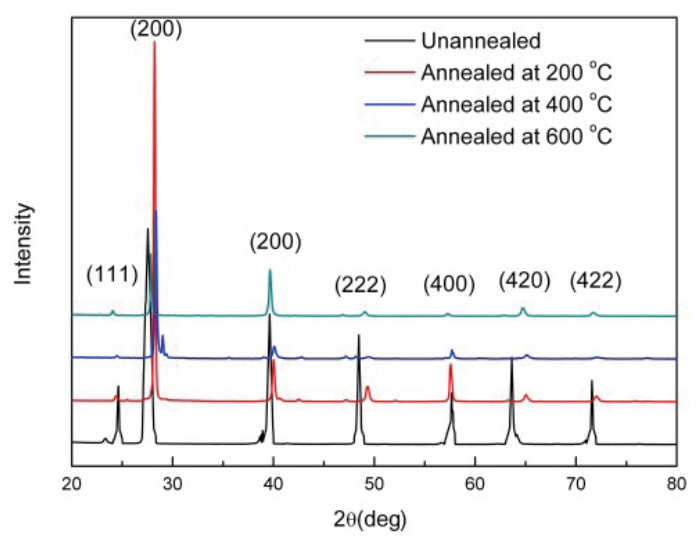

Fig. 1. (Color online) XRD plots of $\mathrm{Ag}_{0.6} \mathrm{~Pb}_{18} \mathrm{Sb}_{5} \mathrm{Te}_{20}$ alloys annealed at 200, 400, and $600{ }^{\circ} \mathrm{C}$. 


\subsection{Surface structure and fracture surface structure}

Figures 2(a)-2(d) show SEM images of fracture surfaces of $\mathrm{Ag}_{0.6} \mathrm{~Pb}_{18} \mathrm{Sb}_{5} \mathrm{Te}_{20}$ alloys annealed at 600,400 , and $200{ }^{\circ} \mathrm{C}$ compared with an unannealed specimen. The clear hexagonal flakes seen in Fig. 2 are probably caused by $\mathrm{Sb}_{2} \mathrm{Te}_{3}$ formed inside the material during melting and annealing. The stripes are created by lattice distortion caused by $\mathrm{PbTe}$, which is predominant in the substrate. Similar stripes have been reported, ${ }^{(12-14)}$ and it has been proposed that the codoping of $\mathrm{Ag}$ and $\mathrm{Sb}$ into $\mathrm{PbTe}$ will cause changes in structure and electron distribution, resulting in partial distortion. This phenomenon is very important for verifying the properties of the material. The change in microstructure is more obvious, showing more vivid stripes on the surface, in the SEM image of test specimens annealed at higher temperatures. Hexagonal flakes are also evident.

\subsection{Seebeck coefficient vs temperature for $\mathrm{Ag}_{0.6} \mathrm{~Pb}_{18} \mathrm{Sb}_{5} \mathrm{Te}_{20}$ alloys annealed at different temperatures}

Figure 3 shows the relationship between Seebeck coefficient and annealing temperature for $\mathrm{Ag}_{0.6} \mathrm{~Pb}_{18} \mathrm{Sb}_{5} \mathrm{Te}_{20}$ alloys annealed at 200,400 , and $600{ }^{\circ} \mathrm{C}$. The measurements were made over a range from room temperature to $458 \mathrm{~K}$. It can be seen that the Seebeck coefficient (the absolute value in Fig. 3) increases as the temperature increases. When heated sufficiently, the electrons, originally in valence bands, are excited by heat over a wide range and acquire sufficient energy to overcome the narrow energy gap.

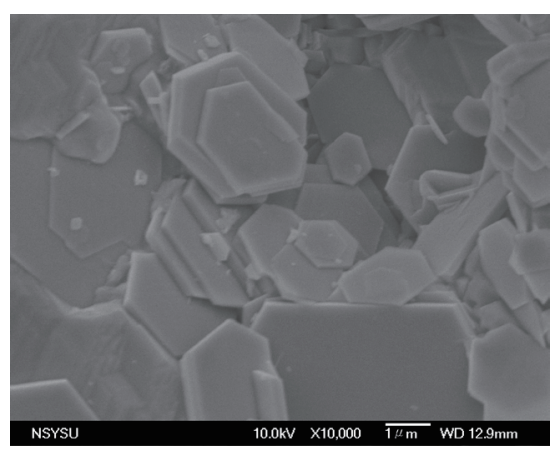

(a)

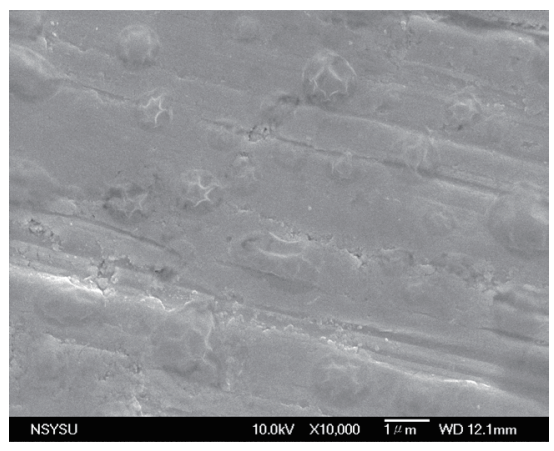

(c)

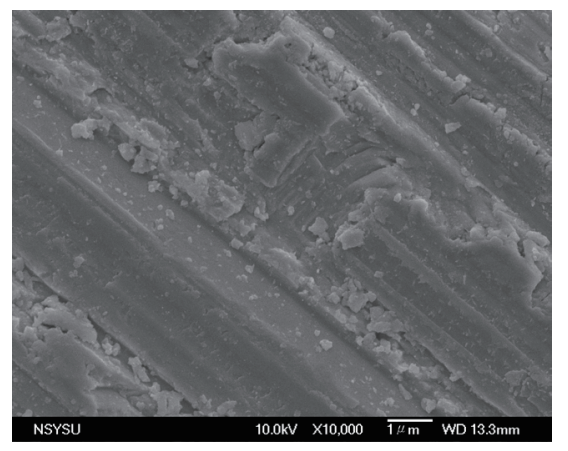

(b)

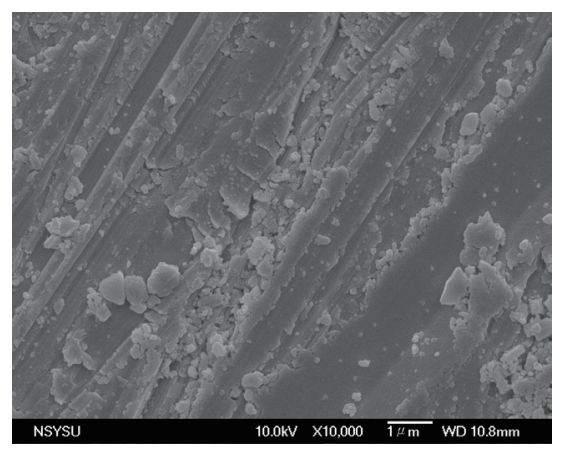

(d)

Fig. 2. SEM images of fracture surface of $\mathrm{Ag}_{0.6} \mathrm{~Pb}_{18} \mathrm{Sb}_{5} \mathrm{Te}_{20}$ annealed at (a) 600 , (b) 400 , and (c) $200{ }^{\circ} \mathrm{C}$, and (d) unannealed. 


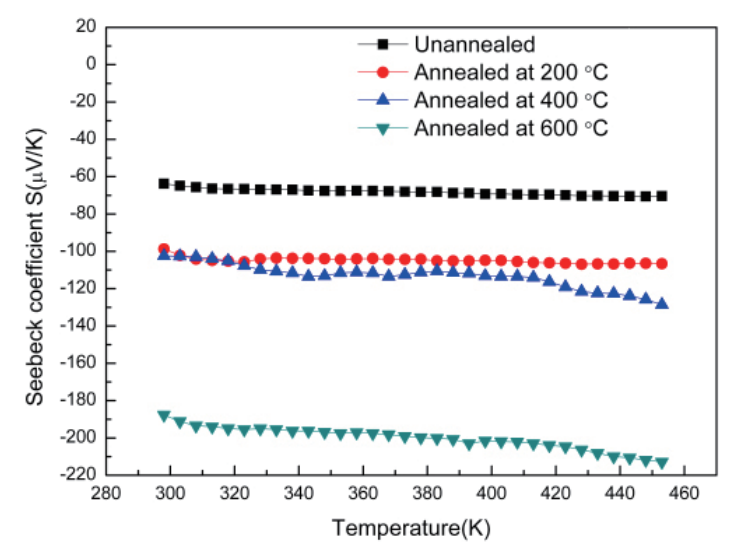

Fig. 3. (Color online) Seebeck coefficient vs temperature in $\mathrm{Ag}_{0.6} \mathrm{~Pb}_{18} \mathrm{Sb}_{5} \mathrm{Te}_{20}$ alloys annealed at different temperatures.

\subsection{Resistivity and temperature of $\mathrm{Ag}_{0.6} \mathrm{~Pb}_{18} \mathrm{Sb}_{5} \mathrm{Te}_{20}$ alloys annealed at different temperatures}

Figure 4 shows the relationship between resistivity and temperature for $\mathrm{Ag}_{0.6} \mathrm{~Pb}_{18} \mathrm{Sb}_{5} \mathrm{Te}_{20}$ alloys annealed at different temperatures. It can be seen that the resistivity decreases as the annealing temperature increases. The findings of Su et al. ${ }^{(15)}$ show that the semiconductor property for the resistivity of PbTe decreases at high temperature, ${ }^{(10)}$ which is very similar to our experimental results. It is our hypothesis that $\mathrm{Ag}$ doping may change the PbTe density of states at the Fermi level.

\subsection{Relationship between power factor and temperature of $\mathrm{Ag}_{0.6} \mathrm{~Pb}_{18} \mathrm{Sb}_{5} \mathrm{Te}_{20}$ alloys annealed at different temperatures}

Figure 5 shows the power factor plotted against temperature for $\mathrm{Ag}_{0.6} \mathrm{~Pb}_{18} \mathrm{Sb}_{5} \mathrm{Te}_{20}$ alloys annealed at different temperatures. The power factor is calculated using the relationship between the Seebeck coefficient and resistivity, and it can be seen to decrease with an increase in temperature. It has been found, ${ }^{(12)}$ that similar phenomena involving PbTe appear at a temperature below $500 \mathrm{~K}$. The power factor increases because a significant decrease in resistivity is accompanied by a decrease in the Seebeck coefficient.

\subsection{Relationship between thermal conductivity and temperature of $\mathrm{Ag}_{0.6} \mathrm{~Pb}_{18} \mathrm{Sb}_{5} \mathrm{Te}_{20}$ alloys annealed at different temperatures}

Figure 6 is a plot of thermal conductivity vs temperature for $\mathrm{Ag}_{0.6} \mathrm{~Pb}_{18} \mathrm{Sb}_{5} \mathrm{Te}_{20}$ alloys annealed at different temperatures. It is seen that the thermal conductivity decreases as the temperature increases. The thermal conductivity of PbTe sintered at atmospheric pressure in our experiment is higher than the $2.3 \mathrm{~W} / \mathrm{mK}$ previously reported. ${ }^{(14)}$ This high thermal conductivity is caused by the higher electronic thermal conductivity $\kappa e$ of $\mathrm{Pb}_{0.55} \mathrm{Te}_{0.45}$, as previously reported, ${ }^{(7)}$ and the conductivity of phonons inside the crystal. The electronic thermal conductivity can be calculated 


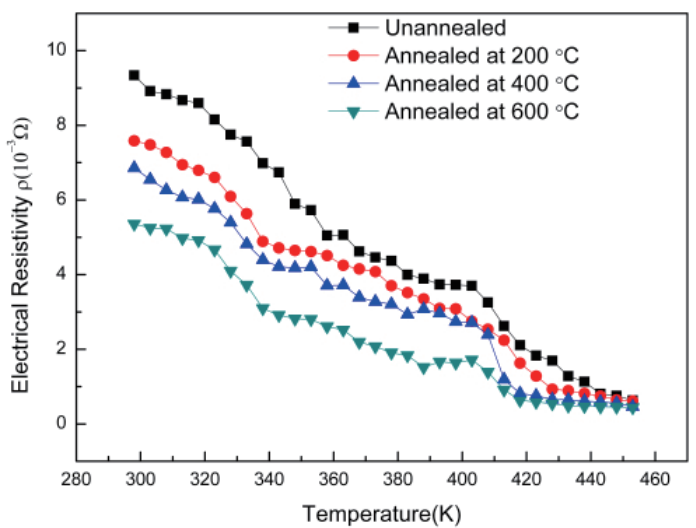

Fig. 4. (Color online) Resistivity vs temperature of $\mathrm{Ag}_{0.6} \mathrm{~Pb}_{18} \mathrm{Sb}_{5} \mathrm{Te}_{20}$ alloys.

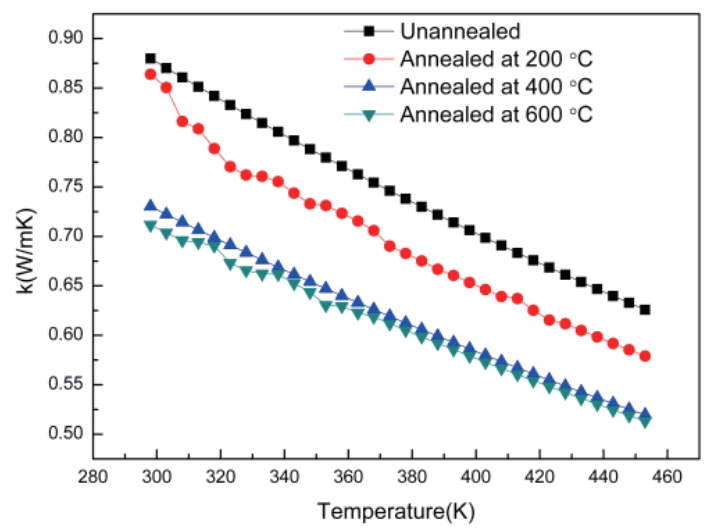

Fig. 6. (Color online) Thermal conductivity vs temperature of $\mathrm{Ag}_{0.6} \mathrm{~Pb}_{18} \mathrm{Sb}_{5} \mathrm{Te}_{20}$ alloys annealed at different temperatures.

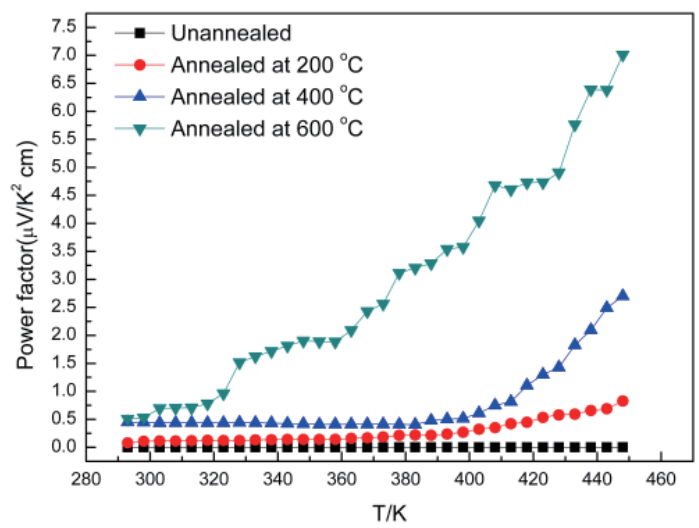

Fig. 5. (Color online) Power factor vs temperature of $\mathrm{Ag}_{0.6} \mathrm{~Pb}_{18} \mathrm{Sb}_{5} \mathrm{Te}_{20}$ alloys annealed at different temperatures.

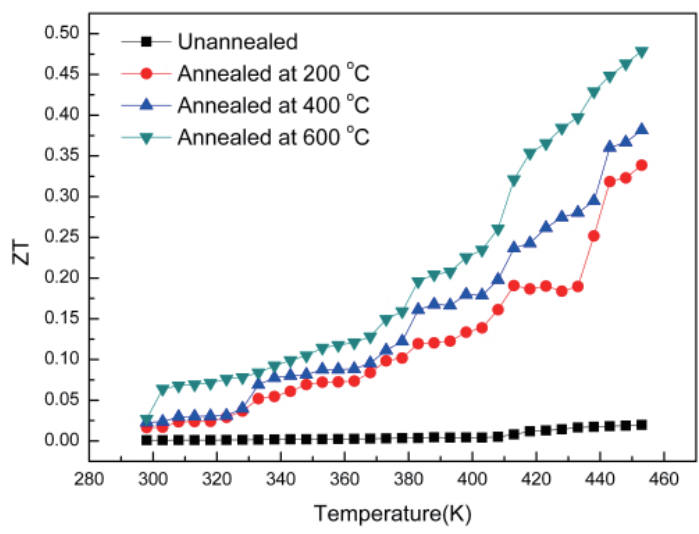

Fig. 7. (Color online) ZT value vs temperature of $\mathrm{Ag}_{0.6} \mathrm{~Pb}_{18} \mathrm{Sb}_{5} \mathrm{Te}_{20}$ alloys annealed at different temperatures.

using the Wiedemann-Franz law, $\kappa e=L \sigma T$, in which $L$ is the Lorenz number $\left(L=2.45 \times 10^{-8}\right.$ $\mathrm{W} \Omega \mathrm{K}^{-2}$ ) and $T$ is the absolute temperature. $\kappa p h$ is then calculated using the relation $\kappa=\kappa e+\kappa p h$. $\mathrm{Ag}_{0.6} \mathrm{~Pb}_{18} \mathrm{Sb}_{5} \mathrm{Te}_{20}$ has lower resistivity and thus higher electronic thermal conductivity.

\subsection{ZT value and temperature of $\mathrm{Ag}_{0.6} \mathrm{~Pb}_{18} \mathrm{Sb}_{5} \mathrm{Te}_{20}$ alloys annealed at different temperatures}

Figure 7 shows the relationship between the $\mathrm{ZT}$ value and the temperature of $\mathrm{Ag}_{0.6} \mathrm{~Pb}_{18} \mathrm{Sb}_{5} \mathrm{Te}_{20}$ alloys annealed at different temperatures. The highest $\mathrm{ZT}$ value of an $\mathrm{Ag}_{0.6} \mathrm{~Pb}_{18} \mathrm{Sb}_{5} \mathrm{Te}_{20}$ alloy, 0.45 , occurs at an annealing temperature of $600{ }^{\circ} \mathrm{C}$. The highest $\mathrm{ZT}$ value is still much lower than that of commercial $\mathrm{PbTe}$, which is 1 . Further improvement is needed. However, these results indicate that a higher annealing temperature gives better thermoelectric properties. Future experiments, which will include adding more Ag to the alloy to improve the thermoelectric properties, are planned. 


\section{Conclusions}

$\mathrm{Ag}$ was added to a substrate of $\mathrm{Pb}_{18} \mathrm{Sb}_{5} \mathrm{Te}_{20}$ to form the quaternary alloy $\mathrm{Ag}_{0.6} \mathrm{~Pb}_{18} \mathrm{Sb}_{5} \mathrm{Te}_{20}$. A comparison of thermoelectric properties between unannealed test pieces and some annealed at different temperatures was conducted. The material used in this experiment was melted under vacuum in an electric arc furnace to form the bulk alloy from which the test pieces were cut and prepared. These were annealed at 200,400 , and $600{ }^{\circ} \mathrm{C}$ in a vacuum annealing furnace for $72 \mathrm{~h}$. Analyses of the composition, microstructure, and thermoelectric properties were then carried out. XRD analysis of the $\mathrm{Ag}_{0.6} \mathrm{~Pb}_{18} \mathrm{Sb}_{5} \mathrm{Te}_{20}$ alloys showed crystal structures similar to FCC. A clear striped structure and flaky hexagonal stacks were seen at the fracture surfaces in SEM images. The stripes are probably the result of lattice distortion caused by $\mathrm{PbTe}$ and $\mathrm{Sb}_{2} \mathrm{Te}_{3}$ structures formed by the precipitation of $\mathrm{Sb}^{3+}$ and $\mathrm{Pb}^{2+}$. The experimental results revealed considerable differences in Seebeck coefficients between the unannealed $\mathrm{Ag}_{0.6} \mathrm{~Pb}_{18} \mathrm{Sb}_{5} \mathrm{Te}_{20}$ test pieces and the annealed ones. Initially, all the thermoelectric properties of the test pieces improved as the annealing temperature increased, but then there was a sharp decline. It is clear that increasing the annealing temperature to improve the thermoelectric properties has a limit. Resistivity measurements showed that the resistivity of the test pieces decreased slightly as the temperature increased and the lowest was $0.44156 \times 10^{-3} \Omega-\mathrm{m}$, which occurred in the test piece annealed at $600{ }^{\circ} \mathrm{C}$. Thermal conductivity measurements also showed a decrease with an increase in annealing temperature, the lowest occurring in the test piece annealed at $600{ }^{\circ} \mathrm{C}$. The highest $\mathrm{ZT}$ value reached in the $\mathrm{Ag}_{0.6} \mathrm{~Pb}_{18} \mathrm{Sb}_{5} \mathrm{Te}_{20}$ tests was 0.45 at $453 \mathrm{~K}$, which is still much lower than that of commercial $\mathrm{PbTe}$, which is 1 . Further improvement is needed. The different ZT values calculated in this experiment may result from the lack of complete mixing in the ball mill, which could result in the incomplete recrystallization of the test pieces. An attempt to improve ZT values in the future may be carried out with fully crystallized test pieces after a more thorough ball milling.

\section{Acknowledgments}

We would like to express our sincere gratitude to the Ministry of Science and Technology, Taiwan, for their support of this research under project number MOST-105-2221-E-151-026.

\section{References}

1 T. Ikeda, S. M. Haile, V. A. Ravi, H. Azizgolshani, and F. Gascoin: Acta Mater. 55 (2007) 1227.

2 Z. G. Huang and J.W. Li: Smart Sci. 4 (2016) 45.

3 R. A. Badwawi, M. Abusara, and T. Mallick: Smart Sci. 3 (2015) 127.

4 K. J. Lo and H. C. Weng: Smart Sci. 3 (2015) 56.

5 K. F. Hsu, S. Loo, F. Guo, W. Chen, J. S. Dyck, C. Uher, T. Hogan, E. K. Polychroniadis, and M. G. Kanatzidis: Science 303 (2004) 818.

6 Z. H. Dughaish: Physica B 322 (2002) 205.

7 G. S. Nolas, J. Sharp, and H. J. Goldsmid: Thermoelectrics: Basic Principles and New Materials Developments (Springer, New York, 2001).

8 T. H. Chen and M. T. Hong: Sens. Mater. 28 (2016) 503.

9 J. H. Yang and T. Caillat: MRS Bull. 31 (2006) 224.

10 T. H. Chen and M.T. Hong: Int. J. Electrochem. Sci. 10 (2015) 9417.

11 D. M. Rowe: Thermoelectrics Handbook: Macro to Nano (CRC Press, Boca Raton, 2006).

12 H. Li, K. F. Cai, H. F. Wang, L.Wang, J. L. Yin, and C. W. Zhou: J. Solid State Chem. 182 (2009) 869.

13 X. Jia, H. Ma, and F. Yu: J. Appl. Phys. 105 (2009) 073713.

14 A. F. Ioffe: Can. J. Phys. 34 (1956) 1342.

15 T. Su, X. Jia, H. Ma, J. Guo, Y. Jiang, N. Dong, L. Deng, X. Zhao, T. Zhu, and C. Wei: J. Alloys Compds. 468 (2009) 410. 


\section{About the Authors}

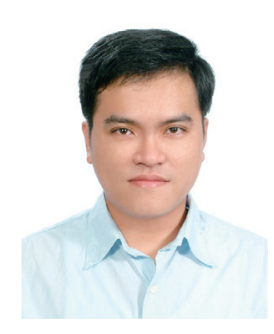

Tao-Hsing Chen received his B.S. degree from National Cheng Kung University, Taiwan, in 1999 and his M.S. and Ph.D. degrees from the Department of Mechanical Engineering, National Cheng Kung University, Taiwan, in 2001 and 2008, respectively. From August 2008 to July 2010, he was a postdoctoral researcher at the Center for Micro/Nano Science and Technology, National Cheng Kung University, Taiwan. Since August 2010, he has been an assistant professor at National Kaohsiung University of Applied Sciences, Taiwan. Since 2016, he has been a professor at National Kaohsiung University of Applied Sciences. His research interests are in metal materials, TCO thin films, and thermal sensors.

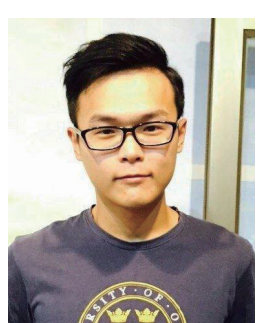

Shiang-An Tsai received his B.S. degree from I-Shou University, Taiwan, in 2012 and his M.S. degree from National Kaohsiung University of Applied Sciences, Taiwan, in 2015. He is now an engineer in an electric company.

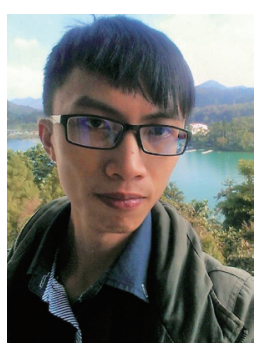

Ting-Yang Zeng received his B.S. degree from National Pingtung University, Taiwan, in 2015 and his M.S. degree from National Kaohsiung University of Applied Sciences, in 2017. He is now serving in the military. 